\title{
Altered profile of circulating endothelial progenitor cells in obstructive sleep apnea
}

\author{
Macy Mei-Sze Lui • Hung-Fat Tse • Judith Choi-Wo Mak • \\ Jamie Chung-Mei Lam • David Chi-Leung Lam • \\ Kathryn C. B. Tan • Mary Sau-Man Ip
}

Received: 10 July 2012 /Revised: 10 October 2012 /Accepted: 22 October 2012 / Published online: 21 November 2012

(C) The Author(s) 2012. This article is published with open access at Springerink.com

\begin{abstract}
Background Obstructive sleep apnea (OSA) is independently associated with endothelial dysfunction, which may be perpetuated by alteration in endothelial repair capacity. Our study evaluates changes in endothelial progenitor cell (EPC) profile in relation to OSA and the role of advanced glycation end-products (AGE) in this relationship.

Methods Consecutive Chinese adults undergoing sleep studies, who had no medical illnesses or regular medications, were enrolled. Subjects with morbid obesity or grossly elevated lipoprotein levels were excluded from analysis. Circulating EPC was measured with flow cytometry analysis.

Results Seventy-two subjects, $64 \%$ with OSA defined by apnea-hypopnea index $(\mathrm{AHI}) \geq 5$, were analyzed. CD34+ cell counts were positively correlated with oxygen desaturation
\end{abstract}

M. M.-S. Lui • H.-F. Tse • J. C.-W. Mak • J. C.-M. Lam •

D. C.-L. Lam • K. C. B. Tan • M. S.-M. Ip ( $\varangle)$

Department of Medicine, Queen Mary Hospital,

The University of Hong Kong,

Pokfulam,

Hong Kong SAR, China

e-mail: msmip@hkucc.hku.hk

M. M.-S. Lui

e-mail: macylui@graduate.hku.hk

H.-F. Tse

e-mail: hftse@hku.hk

J. C.-W. Mak

e-mail: judithmak@hkucc.hku.hk

J. C.-M. Lam

e-mail: lamcmj@hkucc.hku.hk

D. C.-L. Lam

e-mail: dcllam@hku.hk

K. C. B. Tan

e-mail: kcbtan@hku.hk index (ODI) $(r=0.250, p=0.041)$ and duration of oxygen desaturation $<90 \%$ (T90) $(r=0.261, p=0.033)$ and negatively with minimal oxygen saturation $(r=-0.247, p=0.044)$ after adjusting for age, glucose, body weight, and smoking status. AGE was positively correlated with indices of OSA severity (AHI, $r=0.249, p=0.042$; ODI, $r=0.244, p=0.047$; T90, $r=0.243, p=0.047$; minimal oxygen saturation, $r=-0.251, p=0.041)$ and negatively with $\mathrm{CD} 133+$ cells $(r=-0.281, p=0.021)$. On stepwise multiple linear regression analysis, minimal oxygen saturation $(p=0.013)$ and CD133+ cell counts $(p=0.029)$ were found to be significant determinants of AGE level $\left(R^{2}=0.147\right)$.

Conclusions Nocturnal hypoxemia in OSA subjects was associated with increase in endothelial cells (CD34+) which may promote vascular repair. Accumulation of AGE in OSA may lead to diminution in early EPC $(\mathrm{CD} 133+)$ and endothelial repair capacity over time, thus contributing to vascular pathogenesis.

Keywords Advanced glycation end-products · Endothelial progenitor cells $\cdot$ Intermittent hypoxia

\section{Introduction}

Obstructive sleep apnea (OSA) has been shown to predispose to atherosclerotic vasculopathy including coronary artery disease and cerebrovascular accidents and result in increased mortality $[1,2]$. The presence of OSA in healthy subjects without conventional cardiovascular risk factors was associated independently with early signs of atherosclerosis as indicated by carotid-media-intimal thickness [3]. Current knowledge of atherosclerosis suggests that formation of atherosclerotic plagues is preceded by a series of prestructural pathologic events including endothelial dysfunction, 
vascular inflammation, and oxidative stress, which involve complex interplay of many cells and molecules. One such biochemical mediators, namely advanced glycation endproducts (AGE), play a pivotal role in promoting atherosclerosis, especially in the setting of insulin resistance [4]. AGE is generated by nonenzymatic glycation and oxidation of proteins and lipids, in states of heightened oxidative stress and hyperglycemia [5]. AGE triggers a number of cellular cascades that promote endothelial dysfunction and atherosclerosis, including deleterious effects on endothelial progenitor cells (EPC) [6]. We have previously reported that OSA was associated with elevated AGE independent of diabetes or insulin sensitivity [7,8], and this could be reduced with CPAP treatment [9], suggesting that accumulation of AGE may play a role in vascular pathogenesis in OSA.

Endothelial function, often measured noninvasively by endothelial dependent vasodilatation in response to reactive hyperemia, is convincingly shown to be impaired in OSA independent of other risk factors $[10,11]$. The recent discovery of EPC has revolutionized the horizons of regenerative cardiovascular medicine. EPC is believed to reflect another aspect of endothelial function and refers to the group of circulating cells that mediates endothelial repair at sites of vascular injury directly by differentiation into mature endothelial cells, or indirectly by secreting vasoactive substances promoting repair or mediating angiogenesis at sites of ischemia $[12,13]$. Understanding EPC biology in OSA would contribute to the knowledge of vascular pathogenesis in OSA, as well as potential therapeutic interventions to treat incident diseases [14]. Several previous studies have investigated the relationship between OSA and EPC, but results were inconsistent and most were limited by sample size and presence of confounding factors. In the present study, we hypothesized that OSA may alter EPC profile, and this could be related to the accumulation of AGE.

\section{Methods}

\section{Subjects and protocol}

Consecutive healthy adults undergoing overnight polysomnography (PSG) at the Ho Ting Shek Sleep Disorders Center, Queen Mary Hospital, have been prospectively recruited since June 2008 in a study to explore the relation between endothelial dysfunction, circulatory biomarkers of oxidative stress, inflammation, and vascular remodeling in OSA. In the current study which focuses on EPC and AGE, subjects were recruited between October 2008 and March 2011. Exclusion criteria were history of hypertension, diabetes mellitus or hyperlipidemia on medications, atherosclerotic vascular diseases, and other chronic medical diseases; newly detected high blood pressure with systolic blood pressure $>160 \mathrm{~mm} \mathrm{Hg}$ or diastolic blood pressure $>95 \mathrm{~mm} \mathrm{Hg}$ on repeated measurements; regular medications; and acute illnesses, surgical operations, or hospitalizations in the preceding 4 weeks.

All subjects completed a standardized questionnaire assessing Epworth Sleepiness Scale, demographic data, and sleep-related symptoms. After overnight polysomnogram, fasting blood sample was obtained in the morning. Blood samples were sent immediately to the laboratory for the assay of glucose, lipids, and EPC. Blood samples were centrifuged for sera which were stored at $-70{ }^{\circ} \mathrm{C}$ for subsequent batch analysis of AGE.

The study was approved by the Institutional Review Board of the University of Hong Kong and the Hong Kong Hospital Authority Hong Kong West Cluster. All subjects gave written informed consent.

\section{In-hospital overnight polysomnography}

Recruited subjects underwent an overnight attended 16channel PSG (Alice 5 Diagnostics System; Respironics, PA, USA), and the PSG recordings were manually scored by a qualified technologist as previously described [15]. Apnea was defined as complete cessation of airflow for at least $10 \mathrm{~s}$ while hypopnea was defined as at least $30 \%$ reduction in airflow that was associated with at least $4 \%$ drop in oxygen saturation. OSA was defined by apneahypopnea index $(\mathrm{AHI}) \geq 5 / \mathrm{h}$. Oxygen desaturation index (ODI) was defined as the number of episodes per hour of oxygen saturation drop of at least $4 \%$.

\section{Endothelial progenitor cells assay}

Citrated blood was collected from patients and the blood cell composition was measured by Coulter counter (Diff-2R, Beckman Coulter). Then, $100 \mu \mathrm{L}$ of citrated blood was incubated with monoclonal antibodies against human kinase insert domain receptor (KDR) (1:10, R\&D Biosystems; FITC-conjugated), CD133 (1:10, Miltenyi; PE-conjugated), CD34 (1:10, Becton Dickinson; APC-conjugated), and CD45 (1:10, Beckman Coulter; PC7-conjugated) for $30 \mathrm{~min}$. After incubation, blood was lysed and fixed by OptiLyse ${ }^{\circledR} \mathrm{C}$ solution (Beckman Coulter). Isotypic IgG antibodies were used as controls. For multicolor compensation during flow cytometry analysis (FACS), the blood sample was also stained with FITC, PE, APC, and PC7-conjugated monoclonal antibodies against human CD45 to correct for interfluorescent interference. FACS analysis was preformed by FC500 flow cytometer (Beckman Coulter) in which 10,000 events of lymphocyte-like cells were counted. Endothelial progenitor cell parameters were expressed as absolute 
counts of $\mathrm{CD} 34+, \mathrm{CD} 133+, \mathrm{CD} 34+/ \mathrm{KDR}+$, and $\mathrm{CD} 133+/$ $\mathrm{KDR}+$ in total lymphocyte-like population.

Advanced glycation end-products

Serum AGE was measured by competitive enzyme-linked immunosorbent assay (ELISA) using a well-characterized polyclonal rabbit antisera raised by hyperimmunization against AGE-ribonuclease (AGE-RNase), as previously described [7]. This antisera recognizes, as a predominant epitope, the AGE crosslink, ALI (arginine-lysine imidazole). In brief, 96-well plates were coated with $50 \mu \mathrm{L}$ per well of AGE-RNase $(3.75 \mu \mathrm{g} / \mathrm{mL})$. Fifty microliters of serum (1:4 dilution) was added, followed by $50 \mu \mathrm{L}$ of 1:500 diluted anti-AGE antibody. Alkaline phosphate-conjugated antirabbit IgG $(1: 2,000)$ in dilution buffer was added to each well and incubated for $1 \mathrm{~h}$ at $37^{\circ} \mathrm{C}$. After washing, color was developed by the addition of $100 \mu \mathrm{L}$ pNPP substrate (Sigma-Aldrich, St. Louis, MO, USA). Optical density (OD) at $405 \mathrm{~nm}$ was determined by an ELISA reader. Results were calculated as $1-[($ experimental OD - background OD $) /$ (total OD - background OD).]. In our assay, $1 \mathrm{U}$ of AGEs is defined as the amount of AGE present in 1:4 diluted serum that causes $50 \%$ competitive inhibition of anti-AGE antibody binding to coated AGE-RNase on the ELISA plate.

\section{Statistics}

Continuous data in normal distribution were presented as mean \pm standard deviation, or median and interquartile range otherwise. Categoric variables were presented as percentages. Variables not in normal distribution, including AHI, ODI, duration of oxygen saturation $<90 \%$, arousal index, CD133+ count, and CD34+KDR + count were natural log-transformed and parametric statistical tests were used for analysis. Partial correlation analysis was used to explore the association between EPC parameters, sleep parameters, and AGE levels, with adjustments for known confounding variables including age, impaired fasting glucose status (fasting glucose $\geq 5.6$ or $<5.6 \mathrm{mmol} / \mathrm{L}$ ) [16], overweight status (body mass index $\leq 25$ or $>25 \mathrm{~kg} / \mathrm{m}^{2}$ ), and smoking status (current smoker or noncurrent smoker). Stepwise multivariate linear regression analysis using AGE as the dependent variable was used to investigate its relationship with independent variables as listed in Table 2. SPSS 15.0 software was used for the statistical analysis and a $p$ value of $<0.05$ was considered as statistically significant.

\section{Results}

Eighty-five Chinese subjects were recruited according to inclusion and exclusion criteria. Subsequently, those with extreme obesity (BMI $\geq 35 \mathrm{~kg} / \mathrm{m}^{2}, n=3$ ) or grossly elevated low density lipoproteins (LDL $\geq 4.1 \mathrm{mmol} / \mathrm{L}, n=10$ ) were also excluded, as these factors have been reported to significantly affect EPC levels [16] or commonly warrant drug treatment $[17,18]$. Seventy-two subjects (57 men and 15 women) were analyzed. The characteristics of these subjects were listed in Table 1.

Among various EPC parameters, CD34+ cell counts correlated significantly with the severity of nocturnal hypoxemia. Adjusting for age, smoking status, fasting glucose, and weight status as listed above, circulating CD34+ cell counts correlated positively with ODI $(r=0.250, p=0.041)$ and duration of oxygen desaturation $<90 \%(r=0.261$, $p=0.033$ ) and negatively with minimum oxygen saturation ( $r=-0.247, p=0.044)$. There was no significant correlation of CD34+ cell counts with AHI $(r=0.170, p=0.168)$ or arousal index $(r=0.223, p=0.07)$. CD133+ cells and $\mathrm{CD} 133+/ \mathrm{KDR}+$ cells were both positively correlated with arousal index $(r=0.242, p=0.048 ; r=0.291, p=0.017$, respectively) but not with other sleep parameters (Table 2).

AGE levels significantly correlated with indices of OSA severity after adjustment for confounding factors:

Table 1 Characteristics of recruited subjects

\begin{tabular}{|c|c|}
\hline & Overall $(n=72)$ \\
\hline Age (years) & $43.0(10.9)$ \\
\hline Body mass index $\left(\mathrm{kg} / \mathrm{m}^{2}\right)$ & $26.1(3.6)$ \\
\hline \multicolumn{2}{|l|}{ Smoking status } \\
\hline Active smoker & $19.4 \%$ \\
\hline Ex-smoker or nonsmoker & $80.6 \%$ \\
\hline Systolic blood pressure (mm Hg) & $119.1(14.0)$ \\
\hline Diastolic blood pressure $(\mathrm{mm} \mathrm{Hg})$ & $71.9(9.0)$ \\
\hline Total cholesterol (mmol/L) & $4.8(0.7)$ \\
\hline Triglycerides (mmol/L) & $1.5(1.1,2.0)$ \\
\hline Low density lipoprotein $(\mathrm{mmol} / \mathrm{L})$ & $2.8(0.6)$ \\
\hline Fasting glucose (mmol/L) & $5.1(0.6)$ \\
\hline Epworth Sleepiness Scale & $11(7,14)$ \\
\hline Sleep efficiency $(\%)$ & $79.1(12.0)$ \\
\hline Apnea-hypopnea index (events/h) & $7.6(2.2,23.4)$ \\
\hline Duration of oxygen desaturation $<90 \%$ (min) & $3.4(0.1,24.4)$ \\
\hline Oxygen desaturation index (events/h) & $6.3(1.6,19.2)$ \\
\hline Minimal oxygen saturation (\%) & $80.1(12.8)$ \\
\hline Arousal index (events/h) & $14.3(9.0,25.1)$ \\
\hline Advanced glycation end-products (U/mL) & $3.42(0.51)$ \\
\hline CD34+ (cells $/ \mu \mathrm{L})$ & $24.9(10.3)$ \\
\hline CD133+ (cells/ $\mu \mathrm{L})$ & $11.9(6.0,19.2)$ \\
\hline $\mathrm{CD} 34+\mathrm{KDR}+($ cells $/ \mu \mathrm{L})$ & $4.0(2.5,8.5)$ \\
\hline $\mathrm{CD} 133+\mathrm{KDR}+($ cells $/ \mu \mathrm{L})$ & $5.0(3.1,9.0)$ \\
\hline
\end{tabular}

Variables in normal distribution are expressed as mean \pm standard deviation, or median and interquartile ranges for those not in normal distribution 
Table 2 Association between sleep parameters, endothelial progenitor cells, and advanced glycation end-products

\begin{tabular}{|c|c|c|c|c|c|c|}
\hline$p$ values (correlation coefficient) & ODI & T90 & $\mathrm{Min} \mathrm{SaO}_{2}$ & Arousal index & AHI & AGE \\
\hline CD34+ count & $0.041(0.250)$ & $0.033(0.261)$ & $0.044(-0.247)$ & NS & NS & NS \\
\hline CD133+ count & NS & NS & NS & $0.048(0.242)$ & NS & $0.021(-0.281)$ \\
\hline $\mathrm{CD} 133+\mathrm{KDR}+\mathrm{count}$ & NS & NS & NS & $0.017(0.291)$ & NS & NS \\
\hline
\end{tabular}

Number in bracket = correlation coefficient, $A H I$ apnea-hypopnea index, $O D I$ oxygen desaturation index, $T 90$ time with oxygen saturation $<90 \%$, $A G E$ advanced glycation end-products, $\mathrm{Min}_{\mathrm{SaO}}$ minimal oxygen saturation

AHI $(r=0.249, p=0.042)$, ODI $(r=0.244, p=0.047)$, duration of oxygen desaturation $<90 \%(r=0.247, p=0.043)$, and minimum oxygen saturation $(r=-0.251, p=0.041)$. Among various EPC subpopulations, the number of $133+$ cells correlated negatively with AGE levels $(r=-0.281$, $p=0.021)$.

To further analyze the association between EPC, AGE, and sleep parameters, a stepwise multiple linear regression analysis was performed with AGE as dependent variables. Minimal oxygen saturation $(p=0.013)$ and CD133+ counts $(p=0.029)$ were found to be significant independent determinants of AGE level $\left(R^{2}=0.147\right)$ (Table 3$)$.

\section{Discussion}

The current study shows the alteration in EPC profile in relation to indices of OSA severity and levels of AGE, in subjects free of adverse clinical metabolic parameters and overt cardiovascular diseases. Circulating CD34+ cell count increased with severity of intermittent hypoxia, while $\mathrm{CD} 133+$ cell count diminished in correlation with higher AGE levels.

Circulating EPC, which are thought to originate from myeloid pluripotent stem cells, represent the capacity for endothelial regeneration and neovascularization [11, 19]. After being released from bone marrow, they undergo

Table 3 Stepwise multiple linear regression model of advanced glycation end-products

Adjusted $R^{2}=14.7 \%$

\begin{tabular}{llll}
\hline & Adjusted $R^{2}$ & Coefficient beta & $p$ value \\
$\begin{array}{c}\text { Minimal oxygen } \\
\text { saturation }\end{array}$ & $7.1 \%$ & -0.287 & 0.013 \\
CD133+ counts $^{\mathrm{a}}$ & $5.1 \%$ & -0.250 & 0.029 \\
\hline
\end{tabular}

Independent variables included age, current smoking status, overweight status, low density lipoprotein, impaired fasting glucose, apnea-hypopnea inde ${ }^{\mathrm{a}}$, oxygen desaturation inde $\mathrm{x}^{\mathrm{a}}$, duration of oxygen desaturation $<90 \%{ }^{\mathrm{a}}$, arousal index ${ }^{\mathrm{a}}$, minimum oxygen saturation, CD133+ counts $^{\mathrm{a}}, \mathrm{CD} 34+$ counts, CD $34+\mathrm{KDR}+$ counts $^{\mathrm{a}}, \mathrm{CD} 133$

$+\mathrm{KDR}+$ counts $^{\mathrm{a}}$

${ }^{\mathrm{a}} \mathrm{Log}$ transformation before analysis further differentiation with a sequence of changes in their surface antigen (cluster of differentiation, CD), the pattern of which forms the basis of identifying circulating EPC by fluorescence activated cell sorting analysis [20]. CD133+ cells represent the pool of early pluripotent stem cells, which mobilize from bone marrow and differentiate by losing the surface marker and acquiring other markers indicating maturation such as CD34 and/or KDR [13]. CD34+ progenitor cells, sometimes being regarded as late EPC [12], represent more mature endothelial-like cells, which have high angiogenic potential and show the best correlation with cardiovascular risk estimates [21]. Baseline EPC is reduced in the number or becomes dysfunctional in chronic conditions such as aging, hypertension, diabetes, hypercholesterolemia, smoking, and obesity [13]. On the other hand, in response to acute tissue hypoxia such as acute myocardial infarction or unstable angina, there is a physiological surge in circulating EPC levels and homing to damaged sites in order to facilitate repair sequences and new vessel formation in both human and murine studies [22-24]. Advanced glycation end-products have been reported to correlate with reduced number of EPC (CD133+KDR+, CD34+KDR+) in a group of healthy volunteers [6] and to promote EPC dysfunction and apoptosis in vitro [25].

Several previous studies have investigated on the association between OSA and EPC. Findings have been inconclusive, with both negative [26, 27] and positive studies [28-31]. An American study [30] found a lower baseline flow-mediated dilation (FMD) and EPC (CD34+CD133+KDR+) in OSA patients $(n=22)$ when compared to control subjects $(n=15)$, and EPC decreased across tertiles of increasing severity of OSA. Both FMD and EPC increased significantly after CPAP therapy for 4 weeks, while this was not observed in those noncompliant to CPAP therapy. A Japanese casecontrol study has nicely shown that several biomarkers of ischemia-induced angiogenesis or oxidative stress, including angiotensin, vascular endothelial growth factor, oxidized low density lipoprotein, and circulating EPC $(\mathrm{CD} 34+\mathrm{CD} 133+\mathrm{CD} 202 \mathrm{~b}+\mathrm{CD} 45-)$, were increased in the OSA group and decreased after nasal CPAP treatment [28]. A Spanish study also adopted a case-control model and defined EPC as CD34+VEGFR-2+. The authors found a lower EPC level in OSA patients $(n=13)$ compared to 
healthy control $(n=13)$, but no significant correlation was found between EPC and AHI, and the effect of intermittent hypoxia was not reported [29]. On the contrary, another case-control study found no difference in the quantity of $\mathrm{CD} 34+\mathrm{CD} 133+\mathrm{EPC}$ between OSA subjects $(n=17)$ and controls $(n=10)$. In a recent pediatric study, EPC counts (CD34+KDR+VEGFR2+) were reduced concordantly with impaired endothelial function in prepubertal children with OSA compared to control subjects [32], and the difference EPC density appeared to account at least partly to the variation in endothelial functional phenotypes in those with OSA. A study from Korea investigated endothelial colony forming units (CFU) of cultured EPC and found similar levels of CFU in samples from OSA subjects $(n=82)$ compared to controls $(n=22)$, and no correlation between severity of OSA and number of CFU could be identified [27].

In the present study, the increase in CD34+ cells correlating with the severity of nocturnal intermittent hypoxemia is consistent with mobilization of EPC in response to acute hypoxia-reoxygenation injury in these subjects relatively free of conventional cardiovascular risk factors or disease. On the other hand, CD133+ population, which represents immature progenitor cells, was reduced in correlation with higher AGE levels, suggesting that the accumulation of AGE in OSA subjects whose condition remain untreated for a long time could jeopardize the EPC pool and may forebode impairment of vascular repair capacity and endothelial dysfunction. The heterogeneity in findings among various studies could be explained by the adoption of different definitions and quantification methods for EPC populations, and the varying stringency in exclusion of confounding vascular co-morbidities. In the current study, meticulous effort was made to exclude potential confounding risk factors. Polysomnography was manually scored by one dedicated technician not involved in other parts of this study. A larger sample size might allow more reliable analysis and interpretation.

Our findings allow further understanding of vascular pathogenesis in OSA involving EPC and AGE. Reduced ability to trigger endothelial repair mechanisms in response to hypoxic tissue injury can occur at later time points of the natural course of OSA. Further rigorous clinical trials exploring the therapeutic effect of CPAP are awaited.

\footnotetext{
Acknowledgments The authors would like to acknowledge the contribution from the Division of Otorhinolaryngology, Department of Surgery, Queen Mary Hospital, in the collaboration and facilitation of subject recruitment. The authors would like to thank Ms Agnes Lai and Mr Kaiser Sung for data management and statistical assistance and Ms Barbara Law, Ms Michelle Cheong, and staff of the Ho Ting Shek Sleep Disorder Centre, Queen Mary Hospital for technical support. This study is supported by the Hong Kong Research Grants Council (HKU 7582/06M).
}

Open Access This article is distributed under the terms of the Creative Commons Attribution License which permits any use, distribution, and reproduction in any medium, provided the original author(s) and the source are credited.

\section{References}

1. Bradley TD, Floras JS (2009) Obstructive sleep apnoea and its cardiovascular consequences. Lancet 373(9657):82-93

2. Won CH, Chun HJ, Chandra SM, Sarinas PS, Chitkara RK, Heidenreich PA (2012) Severe obstructive sleep apnea increases mortality in patients with ischemic heart disease and myocardial injury. Sleep Breath (in press)

3. Drager LF, Bortolotto LA, Lorenzi MC, Figueiredo AC, Krieger EM, Lorenzi-Filho G (2005) Early signs of atherosclerosis in obstructive sleep apnea. Am J Respir Crit Care Med 172(5):613-618

4. Soldatos G, Cooper ME, Jandeleit-Dahm KA (2005) Advancedglycation end products in insulin-resistant states. Curr Hypertens Rep 7(2):96-102

5. Singh R, Barden A, Mori T, Beilin L (2001) Advanced glycation end-products: a review. Diabetologia 44(2):129-146

6. Ueda S, Yamagishi S, Matsui T, Noda Y, Jinnouchi Y, Sasaki K, Takeuchi M, Imaizumi T (2012) Serum levels of advanced glycation end products (AGEs) are inversely associated with the number and migratory activity of circulating endothelial progenitor cells in apparently healthy subjects. Cardiovasc Ther 30(4):249-254

7. Tan KC, Chow WS, Lam JC, Lam B, Bucala R, Betteridge J, Ip MS (2006) Advanced glycation endproducts in nondiabetic patients with obstructive sleep apnea. Sleep 29(3):329-333

8. Lam JC, Tan KC, Lai AY, Lam DC, Ip MS (2012) Increased serum levels of advanced glycation end-products is associated with severity of sleep disordered breathing but not insulin sensitivity in non-diabetic men with obstructive sleep apnoea. Sleep Med 13 (1): $15-20$

9. Celec P, Hodosy J, Behuliak M, Palffy R, Gardlik R, Halcak L, Mucska I (2012) Oxidative and carbonyl stress in patients with obstructive sleep apnea treated with continuous positive airway pressure. Sleep Breath 16(2):393-398

10. Ip MS, Tse HF, Lam B, Tsang KW, Lam WK (2004) Endothelial function in obstructive sleep apnea and response to treatment. Am J Respir Crit Care Med 169(3):348-353

11. Feng J, Zhang D, Chen B (2012) Endothelial mechanisms of endothelial dysfunction in patients with obstructive sleep apnea. Sleep Breath 16(2):283-294

12. Shantsila E, Watson T, Tse HF, Lip GY (2008) New insights on endothelial progenitor cell subpopulations and their angiogenic properties. J Am Coll Cardiol 51(6):669-671

13. Hristov M, Erl W, Weber PC (2003) Endothelial progenitor cells: mobilization, differentiation, and homing. Arterioscler Thromb Vasc Biol 23(7):1185-1189

14. Dzau VJ, Gnecchi M, Pachori AS, Morello F, Melo LG (2005) Therapeutic potential of endothelial progenitor cells in cardiovascular diseases. Hypertension 46(1):7-18

15. Lam DC, Lui MM, Lam JC, Ong LH, Lam KS, Ip MS (2010) Prevalence and recognition of obstructive sleep apnea in Chinese patients with type 2 diabetes mellitus. Chest 138(5):1101-1107

16. Genuth S, Alberti KG, Bennett P, Buse J, Defronzo R, Kahn R, Kitzmiller J, Knowler WC, Lebovitz H, Lernmark A, Nathan D, Palmer J, Rizza R, Saudek C, Shaw J, Steffes M, Stern M, Tuomilehto J, Zimmet P (2003) Follow-up report on the diagnosis of diabetes mellitus. Diabetes Care 26(11):3160-3167 
17. Muller-Ehmsen J, Braun D, Schneider T, Pfister R, Worm N, Wielckens K, Scheid C, Frommolt P, Flesch M (2008) Decreased number of circulating progenitor cells in obesity: beneficial effects of weight reduction. Eur Heart J 29(12):1560-1568

18. Gotto AM Jr, Kuller LH (2002) Eligibility for lipid-lowering drug therapy in primary prevention: how do the Adult Treatment Panel II and Adult Treatment Panel III Guidelines compare? Circulation 105(2):136-139

19. Fadini GP, Agostini C, Sartore S, Avogaro A (2007) Endothelial progenitor cells in the natural history of atherosclerosis. Atherosclerosis 194(1):46-54

20. Yoder MC (2009) Defining human endothelial progenitor cells. J Thromb Haemost 7(Suppl 1):49-52

21. Fadini GP, de Kreutzenberg SV, Coracina A, Baesso I, Agostini C, Tiengo A, Avogaro A (2006) Circulating CD34+ cells, metabolic syndrome, and cardiovascular risk. Eur Heart J 27(18):22472255

22. Ong LL, Li W, Oldigs JK, Kaminski A, Gerstmayer B, Piechaczek C, Wagner W, Li RK, Ma N, Steinhoff G (2010) Hypoxic/normoxic preconditioning increases endothelial differentiation potential of human bone marrow CD133+ cells. Tissue Eng Part C Methods 16 (5):1069-1081

23. Gharib SA, Dayyat EA, Khalyfa A, Kim J, Clair HB, Kucia M, Gozal D (2010) Intermittent hypoxia mobilizes bone marrowderived very small embryonic-like stem cells and activates developmental transcriptional programs in mice. Sleep 33 (11):1439-1446

24. Kamota T, Li TS, Morikage N, Murakami M, Ohshima M, Kubo M, Kobayashi T, Mikamo A, Ikeda Y, Matsuzaki M, Hamano K (2009) Ischemic pre-conditioning enhances the mobilization and recruitment of bone marrow stem cells to protect against ischemia/reperfusion injury in the late phase. J Am Coll Cardiol 53(19):1814-1822
25. Chen J, Song M, Yu S, Gao P, Yu Y, Wang H, Huang L (2010) Advanced glycation endproducts alter functions and promote apoptosis in endothelial progenitor cells through receptor for advanced glycation endproducts mediate overpression of cell oxidant stress. Mol Cell Biochem 335(1-2):137-146

26. Martin K, Stanchina M, Kouttab N, Harrington EO, Rounds S (2008) Circulating endothelial cells and endothelial progenitor cells in obstructive sleep apnea. Lung 186(3):145-150

27. Yun CH, Jung KH, Chu K, Kim SH, Ji KH, Park HK, Kim HC, Lee ST, Lee SK, Roh JK (2010) Increased circulating endothelial microparticles and carotid atherosclerosis in obstructive sleep apnea. J Clin Neurol 6(2):89-98

28. Kizawa T, Nakamura Y, Takahashi S, Sakurai S, Yamauchi K, Inoue H (2009) Pathogenic role of angiotensin II and oxidised LDL in obstructive sleep apnoea. Eur Respir J 34(6):1390-1398

29. de la Pena M, Barcelo A, Barbe F, Pierola J, Pons J, Rimbau E, Ayllon O, Agusti AG (2008) Endothelial function and circulating endothelial progenitor cells in patients with sleep apnea syndrome. Respiration 76(1):28-32

30. Jelic S, Padeletti M, Kawut SM, Higgins C, Canfield SM, Onat D, Colombo PC, Basner RC, Factor P, LeJemtel TH (2008) Inflammation, oxidative stress, and repair capacity of the vascular endothelium in obstructive sleep apnea. Circulation 117(17):2270-2278

31. Jelic S, Lederer DJ, Adams T, Padeletti M, Colombo PC, Factor P, Le Jemtel TH (2009) Endothelial repair capacity and apoptosis are inversely related in obstructive sleep apnea. Vasc Health Risk Manag 5:909-920

32. Kheirandish-Gozal L, Bhattacharjee R, Kim J, Clair HB, Gozal D (2010) Endothelial progenitor cells and vascular dysfunction in children with obstructive sleep apnea. Am J Respir Crit Care Med 182(1):92-97 